Neupane $Y$

Guragain RPS

Khallilullah S

Prakash S

Ganesh Man Singh Memorial Academy of ENT and Head and Neck Studies, TU Teaching Hospital, Kathmandu, Nepal.

Correspondence to:

Dr Yogesh Neupane

Ganesh Man Singh Memorial Academy of ENT and Head and Neck Studies, TU Teaching Hospital, Kathmandu,

Nepal.

E-mail: yogeshneupane@hotmail.com

\section{ROLLING AUDIT: PATIENT'S SATISFACTION FOR SERVICES PROVIDED IN ENT WARD}

Objectives:

To measure patient's satisfaction for services provided in ENT ward, ENT-HNS department of TU, Teaching hospital, to compare the patient's satisfaction of this present rolling audit to previous rolling audit and also to observe implementation of recommendations made by previous rolling audit. Material and Methods:

A cross sectional descriptive study was conducted during March/April 2009. Study was based on administered questionnaire which was translated in simple local language. Patients were randomly given the questionnaire at the time of admission and were requested to fill the form completely and return at the time of discharge. Data was collected and analyzed.

Results:

Things of concern in this study were that $28 \%$ of patients still had to wait more than 1 hour to get their allocated bed in ward after admission, behavior of doctors and nursing staffs was not good to $10 \%$ of the patient, $21 \%$ of patients were poorly explained about side effects of medication, benefits and complication of surgery, $11 \%$ of patient couldn't enquire about their treatment to their doctors, $9 \%$ felt that ENT ward was dirty, $27 \%$ found arrangement for prevention of insects was poor. According to $13 \%$ of patient hospital food was of low standard and $20 \%$ felt that hospital environment was noisy. $8 \%$ of patients were not happy about the explanation made to them about the medication, precaution to be taken at home and about their follow up at the time of discharge. $10 \%$ of patients were annoyed by ill treatment done to them during their hospital stay. There was no significant implementation of recommendation laid by previous rolling audit.

Conclusion:

Providing the patients/clients opportunity to voice their opinions about the care they receive can be seen as part of a broader commitment to public and patient/client participation in health care service planning and delivery. Rolling audit must be done at regular basis to implement change and further monitoring to confirm improvement.

Key words: Patient satisfaction, Audit,

\section{INTRODUCTION:}

Satisfaction is a psychological concept which is easy to understand but hard to define. Simple and practical definition would be the degree to which desired goals have been achieved. Patient/client satisfaction is an attitude i.e. a person's general orientation towards a total experience of health care, which comprises both cognitive and emotional facets and relates to previous experiences, expectations and social network. ${ }^{1}$ Satisfaction is achieved when patient/clients perception of the quality of care and services that they receive in healthcare setting has been positive, satisfying and meets their expectation. Audit is a systematic critical analysis of the quality of medical care, including the procedures used for diagnosis and treatment, the use of resources and the resulting outcome and quality of life for the patient. Proper record keeping is of increasing importance in medical field. One of first ever clinical audits was undertaken by Florence Nightingale during the Crimean War of 1853-1855 healthcare delivery. The National Institute for Health and Clinical Excellence (NICE) defines clinical audit as a quality improvement process that seeks to improve patient care and outcomes through systematic review of care against explicit criteria and the implementation of change. Aspects of the structure, processes, and outcomes of care are selected and systematically evaluated against explicit criteria. Where indicated, changes are implemented at an individual, team, or service level and further monitoring is used to confirm improvement. According to General Medical Council we must work with colleagues to monitor and maintain the quality of the care we provide and maintain a high awareness of patient safety. In particular, we must take part in regular and systematic medical and clinical audit, recording data honestly. There is a growing need to keep records in medical fields since doctor have to justify their patient management in malpractice claims $s^{2,3}$ One of the significant trends in the development of modern healthcare is the involvement of patient/clients in the management of their care and treatment. Some patient may have an occasional intervention while others have a permanent and long term relationship with a service provider depending on the nature and extent of their need. Person centered health care respects the dignity and value of each person. A person centered health system identifies and responds to the needs of individuals' plans and delivers health care in a coordinated way and helps individual to participate in decision making to improve their health. Feedback from patients/clients provides crucial information on what the patients/clients expectations are and how they perceive the quality of care, which may be different from that of all staff providing that care. To capture patient/client voice is essential element of policy making. According to survey by Irish society for quality and safety in healthcare, concept of people centeredness has become an increasingly important feature of how we plan and deliver health care. The objective of this study was to measure patients satisfaction for services provided in ENT ward, ENT-HNS, department of TU, Teaching hospital, to compare the patients satisfaction of this present rolling audit to previous rolling audit and also to observe implementation of recommendations made by previous rolling audit.

\section{MATERIALS AND METHODS:}

A cross sectional descriptive study was conducted in ENT ward, ENTHNS department, TU Teaching Hospital during March/April 2009. Topic was selected and twenty one questions were prepared, each question was provided with suitable optional answers. Questionnaire was translated in simple local language. Patients were randomly given the questionnaire at the time of admission and were requested to fill the form completely and return at the time of discharge. Patient's guardian or caretakers were requested to help the patient if required. Data was collected and analyzed. Implementation of recommendation laid by previous rolling audit was analyzed and compared with present audit

\section{RESULTS:}

A total of 210 answered questionnaire forms/ sheets were included in the study. All the questions in questionnaire were not completely answered, so the data are shown both in numbers and percentage of

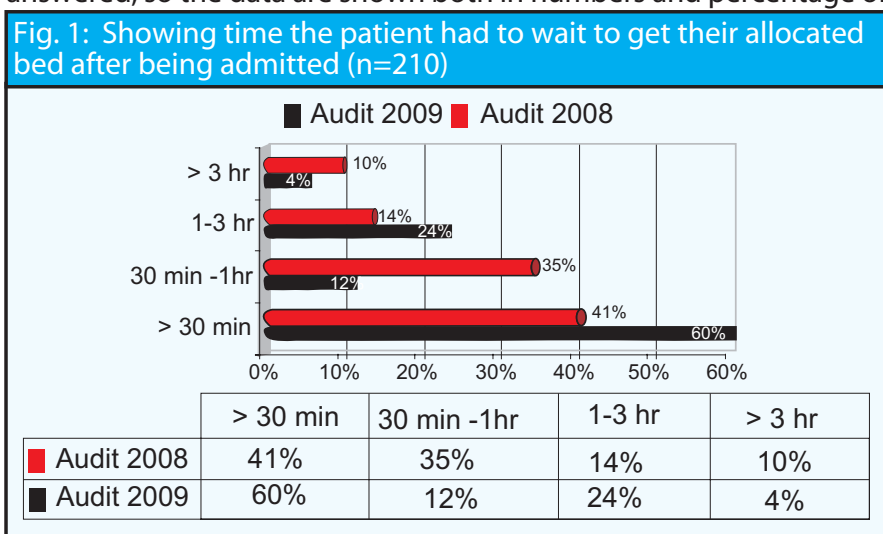


those who responded to the particular question. Among 210 patients $135(64 \%)$ filled the form themselves but $75(36 \%)$ were filled by family members. $19 \%$ of the responder were of less than 13 years of age $47 \%$ were of $13-29$ years old, $19 \%, 6 \%, 10 \%$ were respectively of 30 40 years, $45-59$ years and above 60 years of age. After admission $60 \%$ of patient had to wait less than 30 minutes to get their allocated bed, $12 \%, 24 \%, 4 \%$ had to wait 30 minutes to 1 hour, 1 to 3 hours, more than 3 hours respectively (Fig.1). Delay in clearance of previous patient to vacant the bed was most common reason to wait for more than 30 minutes. During hospital stay $42 \%$ of patients rated the behavior of doctors and nursing staffs toward them was very good, $48 \%$ rated good, $9 \%$ and $1 \%$ rated as ok and poor respectively (Fig. 2). Fig. 2: Showing the patient response about the behavior of doctor and nursing staff toward patient. $(n=210)$

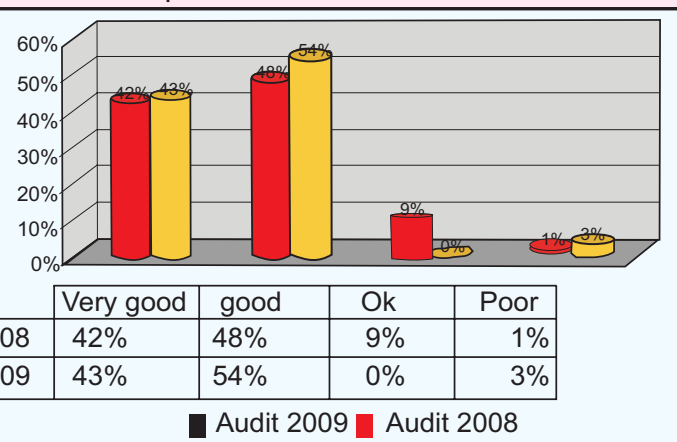

$37 \%$ felt that they were very well explained about their treatment, $55 \%$ felt it was well explained but $8 \%$ complained that they were poorly explained (Tab.1).

Tab. 1: Patients response to explanation given to them about their treatment

\begin{tabular}{|l|c|c|}
\hline $\begin{array}{l}\text { How well were you } \\
\text { explained about your } \\
\text { treatment? }(\mathrm{n}=210)\end{array}$ & Audit 2009 & Audit 2008 \\
\hline Very Well explained & $37 \%$ & $31.62 \%$ \\
\hline Well explained & $55 \%$ & $61.68 \%$ \\
\hline Poorly explained & $8 \%$ & $6.70 \%$ \\
\hline
\end{tabular}

When asked the time taken by nursing staff to reach them after calling them for help; $70 \%$ of patient replied that nursing staff took less than 5 minutes, $27 \%, 2 \%$ replied that they took 5 to 30 minutes, more than 30 minutes respectively but $1 \%$ was unhappy as their calls were not responded (Tab. 2).

\begin{tabular}{|c|c|c|}
\hline $\begin{array}{l}\text { How long did nursing staff } \\
\text { take to reach you } \\
\text { after calling? }(n=210)\end{array}$ & Audit 2009 & Audit 2008 \\
\hline Very fast ( $<5 \mathrm{~min})$ & $70 \%$ & $45 \%$ \\
\hline After some time(5-30min) & $27 \%$ & $48.33 \%$ \\
\hline Late $(>30 \mathrm{~min})$ & $2 \%$ & $6.67 \%$ \\
\hline Didn't come & $1 \%$ & $0 \%$ \\
\hline
\end{tabular}

Similarly when asked the time taken by the duty doctor to respond the patients call; $60 \%$ replied that time taken was less than 5 minutes, $38 \%$ replied that it was between 5 to 30 minutes and 2\% complained that duty doctor didn't respond to their call (Tab.3).

Tab. 3: Showing time taken by duty doctor to respond patient call

\begin{tabular}{|l|c|c|}
\hline $\begin{array}{l}\text { How long did Doctor on } \\
\text { duty take to reach you } \\
\text { after calling? }(\mathrm{n}=210)\end{array}$ & Audit 2009 & Audit 2008 \\
\hline Very fast (<5min) & $60 \%$ & $46.67 \%$ \\
\hline After some time(5-30min) & $38 \%$ & $40 \%$ \\
\hline Late (>30min) & $0 \%$ & $8.33 \%$ \\
\hline Didn't come & $2 \%$ & $5 \%$ \\
\hline
\end{tabular}

Tab. 4: Showing patients views to the explanation made to them about the drugs and nature of disease

\begin{tabular}{|l|c|c|}
\hline $\begin{array}{c}\text { How well were you explained about? } \\
\text { benefits and the complications of the surgery } \\
\text { side effects of the medications ( } \mathrm{n}=180)\end{array}$ & Audit 2009 & Audit 2008 \\
\hline Very well explained & $28 \%$ & $26.6 \%$ \\
\hline Well explained & $51 \%$ & $56.6 \%$ \\
\hline Poorly explained & $21 \%$ & $16.8 \%$ \\
\hline
\end{tabular}

Tab.5: Showing patients perception to the communication among the doctors, nurses and staff about their diseases and treatment.

\begin{tabular}{|l|l|l} 
How was the communication among & Audit 2009 & Audit 2008
\end{tabular} the doctors, nurses and staffs about your disease and treatment? $(n=205)$

\begin{tabular}{|l|l|l|}
\hline Very good & $25 \%$ & $28.4 \%$ \\
\hline Good & $74 \%$ & $65 \%$ \\
\hline Poor & $1 \%$ & $6.6 \%$ \\
\hline
\end{tabular}

Tab. 6: Showing how well the patient's privacy was respected.

\begin{tabular}{|l|c|c|}
\hline $\begin{array}{l}\text { How well was your privacy } \\
\text { respected? }(\mathrm{n}=200)\end{array}$ & Audit 2009 & Audit 2008 \\
\hline Very well respected & $21 \%$ & $28.34 \%$ \\
\hline Respected & $77 \%$ & $65 \%$ \\
\hline Not respected & $2 \%$ & $6.66 \%$ \\
\hline
\end{tabular}

Tab. 7: Showing response to patients ability to enquire about their treatment.

\begin{tabular}{|l|c|c|}
\hline $\begin{array}{l}\text { How much were you able to } \\
\text { enquire about your treatment? }\end{array}$ & Audit 2009 & Audit 2008 \\
\hline Could enquire a lot & $40 \%$ & $13.33 \%$ \\
\hline Could enquire & $49 \%$ & $50 \%$ \\
\hline Couldn't enquire & $11 \%$ & $36.67 \%$ \\
\hline
\end{tabular}

Tab. 8: Showing patients response to arrangement for prevention of insects in ENT ward.

\begin{tabular}{|l|c|c|}
\hline $\begin{array}{l}\text { How were the arrangement for } \\
\text { prevention of insects ? }(\mathrm{n}=200)\end{array}$ & Audit 2009 & Audit 2008 \\
\hline Very good & $16 \%$ & $12 \%$ \\
\hline Good & $57 \%$ & $53 \%$ \\
\hline Poor & $27 \%$ & $35 \%$ \\
\hline
\end{tabular}

Tab. 9: Showing patient response to drinking water facility in ENT ward

\begin{tabular}{|l|l|l|}
\hline $\begin{array}{l}\text { How was the facility of } \\
\text { drinking water? }(n=190\end{array}$ & Audit 2009 & Audit 2008 \\
\hline Very good & $12 \%$ & $29 \%$ \\
\hline Good & $54 \%$ & $53 \%$ \\
\hline Poor & $34 \%$ & $18 \%$ \\
\hline
\end{tabular}

\begin{tabular}{l}
\hline $\begin{array}{l}\text { Tab. 10: Showing how peaceful the patient felt the hospital } \\
\text { environment was? }\end{array}$ \\
\begin{tabular}{l|c|c|}
\hline $\begin{array}{l}\text { How peaceful was the hospital's } \\
\text { environment? (n=200) }\end{array}$ & Audit 2009 & Audit 2008 \\
\hline Very peaceful & $12 \%$ & $20 \%$ \\
\hline Quiet & $69 \%$ & $60 \%$ \\
\hline Noisy & $19 \%$ & $20 \%$ \\
\hline
\end{tabular}
\end{tabular}




$\begin{aligned} & \text { Tab. 11: Patients response to the ill treatment they faced during } \\
& \text { their hospital stay }\end{aligned}$
\begin{tabular}{|l|c|c|}
\hline $\begin{array}{l}\text { Were you ill treated by anyone } \\
\text { during your hospital stay? }(\mathrm{n}=190)\end{array}$ & Audit 2009 & Audit 2008 \\
\hline Yes & $19(10 \%)$ & $6(10 \%)$ \\
\hline No & $171(90 \%)$ & $54(90 \%)$ \\
\hline
\end{tabular}

Tab. 12: Showing patients wish to visit this hospital again.

\begin{tabular}{|l|l|l|}
\hline $\begin{array}{l}\text { Would you like to visit this } \\
\text { hospital again for your ENT } \\
\text { problems? }(\mathrm{n}=200 \text { ) }\end{array}$ & Audit 2009 & Audit 2008 \\
\hline Will come to this hospital only & $69 \%$ & $47 \%$ \\
\hline Will come here if possible & $30 \%$ & $37 \%$ \\
\hline Will go to a place at my own ease & $1 \%$ & $16 \%$ \\
\hline Will never come to this hospital & 0 & 0 \\
\hline
\end{tabular}

$28 \%$ of patient replied that they were very well explained, $51 \%$ well explained and $21 \%$ poorly explained about side effects of drugs, benefits and complications of surgery (Tab. 4). $40 \%$ of patients were happy that they could enquire a lot about their treatment, $49 \%$ told they could enquire to some extend but $11 \%$ of patient were unsatisfied as they couldn't enquire about their treatment (Tab. 7). $25 \%$ of patients felt that there was very good, $74 \%$ good and $1 \%$ felt that there was poor communication among doctors, nurses and staffs about patient disease and treatment (Tab. 5). 21\% were happy as their privacy was very well respected, $77 \%$ of patient felt it was well respected and $2 \%$ patient felt it was not respected at all (Tab. 6). 63\%, 35\% and 2\% of patient found their treating doctor very trustworthy, trustworthy, not trustworthy respectively (Fig. 3)

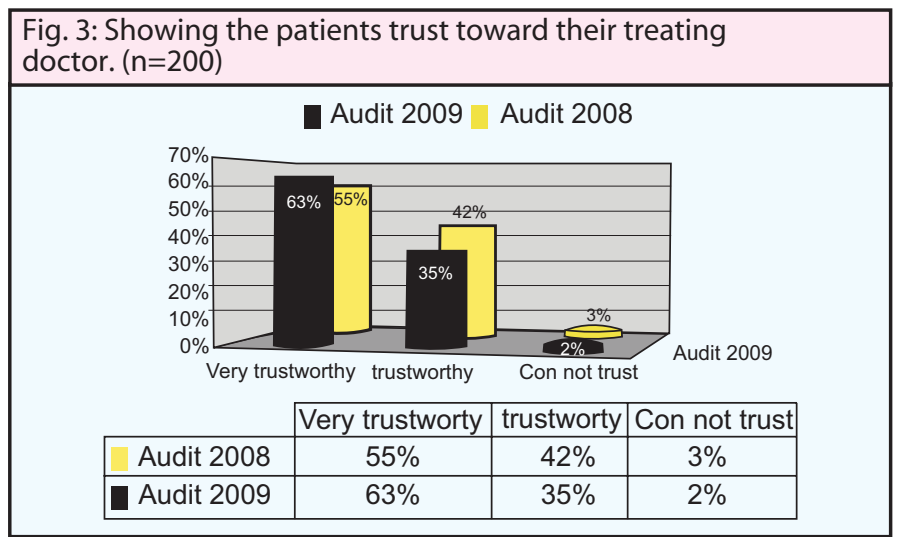

Fig. 4: showing patients rating about the cleanliness of ward. $(n=210)$

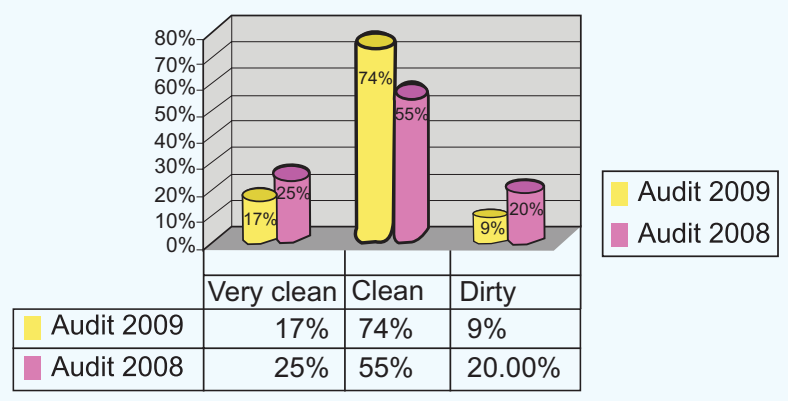

Patients were also enquired about various aspect of physical environment of hospital. Regarding the cleanliness of ENT ward only $17 \%$ rated it very clean though $74 \%$ rated it clean but still $9 \%$ rated it dirty (Fig. 4).16\% of patient found that arrangement for prevention of insect to be very good, $57 \%$ found it good but $27 \%$ of patient

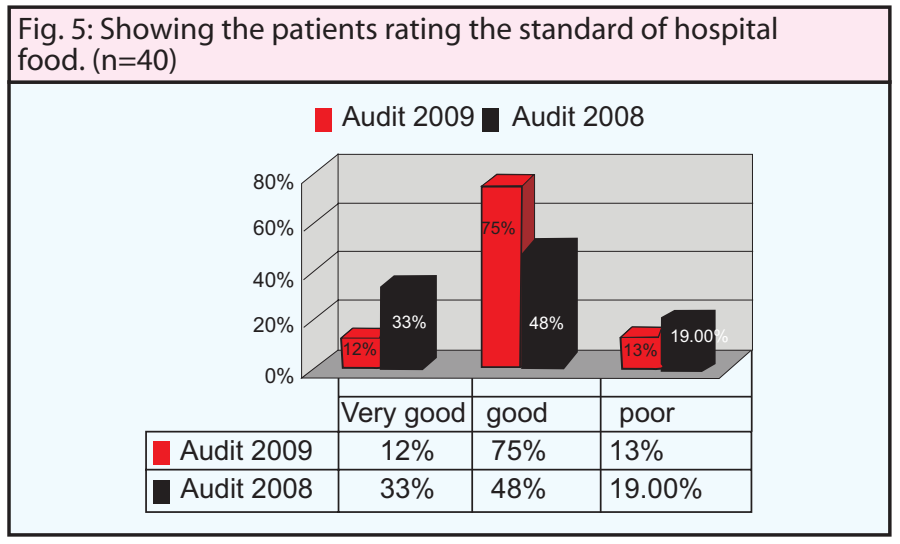

Fig. 6: Showing the patients response to explanation about the medications \& precautions to be taken at home and about the follow-up? $(n=200)$

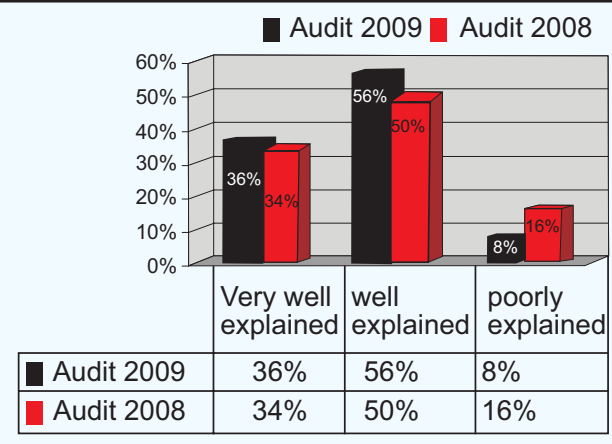

complain that those measures were poor (Tab. 8). Standard of hospital food was found to be good by $75 \%$ of patient, very good by $12 \%$ and poor by $13 \%$ of patients (Fig. 5). $66 \%$ of patients rated the facility of drinking water in ENT ward was good but $34 \%$ complained it to be poor. $69 \%$ found that hospital environment to be quiet, $12 \%$ found it to be very peaceful but 19\% complained of noisy hospital environment (Tab. 10). 10\% of patient complained that they were ill treated by someone during their hospital stay and $90 \%$ of those who were ill treated complained sweepers ill treating them (Tab.11).

During discharge $56 \%, 36 \%, 8 \%$ replied that they were well explained, very well explained and poorly explained respectively about the medications and precaution to be taken at home and about the followup (Fig 6). 69\% of patient replied that they would come to this hospital only, $30 \%$ replied that if possible they will come to this hospital and $1 \%$ will go to the hospital of their own ease for their future ENT problems (Tab.12). The recommendations that were made in previous rolling audit were; provision of complain form and collection box in ENT-ward, regular fumigation of treatment room and ward, improvement of physical environment especially cleanliness of ward, installation of coin telephone set in ward for care taker and patient ease, upgrading the standard of name plates with patient update and conduction of rolling audit in every six month. Implementation of recommendation made by previous rolling audit was also analyzed in this rolling audit. Recommendation which were implemented was improved physical environment and up gradation of standard of names plates with patient update. Provision of complain form and collection box in ENT ward, regular fumigation of ward, installation of coin telephone set and conduction of regular rolling audit were those recommendation which were not implemented.

\section{DISCUSSION:}

Consumer participation is increasingly being linked with improvements in the quality of healthcare and improved health outcomes. There is an increasing impetus for shared decision making and person centered care. Person centered care has become a central concept in health care as a response to; a general trend towards increasing attention to social inclusiveness and needs of the consumer, rapidly increasing cost of healthcare, focus on improvement of processes and outcome of care ${ }^{4}$, increased access of patients/clients to information about 
healthcare treatment and option 5 . There is a growing evidence of the links between consumer feedback and participation in decision making in individual care leads to improvement in health outcomes 6,7 and stronger therapeutic alliances. Effective consumer feedback strategies make organizations more aware of significant areas of dissatisfaction with care and services ${ }^{8}$, give staff new insight into how people perceive aspects of their care and increase consumer confidence 9. Patients/clients and their families hold unique vantage points as expert witnesses of care, so their satisfaction is now a critical variable in measurement of any quality of care. To include patients/clients evaluations of care is growing as more providers/ organization realize that patient/ client satisfaction measurement is a cost effective, noninvasive indicator of quality of care. Rolling audit is very important to improve the quality of patient care and to maintain a high awareness of patient safety.

In this present study patient's satisfaction for services provided in ENT ward in various aspect was measured and analyzed. Total of 210 patients/caretaker who were admitted in ENT ward, ENT-HNS department, TU teaching Hospital for ENT related problems took part in this study. Study was done for period of 2 months and patients were randomly selected to decrease the biasness of the study. Things of concern in this study were that $28 \%$ of patients still had to wait more than 1 hour to get their allocated bed in ward after admission, behavior of doctors and nursing staffs was not good to $10 \%$ of the patient, $21 \%$ of patients were poorly explained about side effects of medication, benefits and complication of surgery, $11 \%$ of patient couldn't enquire about their treatment to their doctors, $9 \%$ felt that ENT ward was dirty, $27 \%$ found arrangement for prevention of insects was poor. According to $13 \%$ of patient hospital food was of low standard and $20 \%$ felt that hospital environment was noisy. $8 \%$ of patients were not happy about the explanation made to them about the medication, precaution to be taken at home and about their follow up at the time of discharge.10\% of patients were annoyed by ill treatment done to them during their hospital stay.

Things that were improved than previous audit were patient wish to visit this hospital again for their future ENT problem, cleanliness of ward, patient's ability to enquire about their treatment, medication and side effect of drugs. Arrangement for prevention of insects, standard and quality of hospital food, explanation about precaution to be taken at home and about the follow up are also the improved aspects. Though these were improved but they are still the things of concern.

There were no significant implementations of recommendation made by previous rolling audit. Though there was improved cleanliness of ENT ward and up gradation in standard of name plates with patient update but provision of complain form and collection box, installation of coin telephone set, regular fumigation of treatment room and ward and conduction of regular rolling audit were among the things that were not implemented.

\section{CONCLUSION:}

Evaluation of patient satisfaction should form part of continuous improvement. Patient satisfaction, as a method of evaluating health services is essential. Understanding the differences between costumers needs and costumers satisfaction is crucial to organization's success in quality management. Providing the patients/clients as opportunity to voice their opinions about the care they receive can be seen as part of a broader commitment to public and patient/client participation in health care service planning and delivery. Recommendation are made for regular rolling audit at least 6 monthly, regular fumigation of ward and treatment room, improvement in efficacy of ward services so that patient can get allocated bed on time after admission, team effort to improve physical environment of ward, improve doctorpatient/ caretaker interaction, provision of adequate time for patient to explain them about their treatment and solving their queries, proper explanation of side effects of drugs, outcome/complication of disease, benefit and complication of surgery to patients and their caretaker

REFERENCES:

1. Keegan, O., McDarby, V, Tansey, A., and McGee, H., 2003. Community involvement in A/E satisfaction survey. [Submitted for puplication.]

2. Panting G. How to avoid being sued in clinical practice. Postgrad Med J.2004 Mar; 80(941): 165-8.

3. Hutchinson G, Sharples C. Information Governance: Practical implication for record keeping. Nurs Stand. 2006 May; 20(36): 5964.

4. Al-Assaf, A.F., Schmele, J.A.,eds., 1993. The textbook of total quality in healthcare. Delray Beach: St. Lucie.

5. Bowers, B. and Lutz, B., 2000. Patient-centered care: Understanding its interpretation and implementation in health care. Philadelphia: WB Saunders Co

6. England, S., \& Evans, J., 1992, 'Patients' choices and perceptions after an invitation to participation in treatment decisions, Social Science Medicine, 34:1217-1225

7. Fallowfield, L., Hall, A., Maguire G., \& Baum, M., 1990, Psychological outcomes of different treatment policies in women with early breast cancer outside a clinical trial. British Medical Journal, 301:575580.

8. Ovretveit J., 1998. Evaluating health interventions: an introduction to evaluation of health treatments, services, policies and organisational interventions. Buckingham: Open University Press.

9. Draper, M., 1997. Involving consumer in improving hospital care: lessons from Australian hospitals. Commonwealth Department of Health and Family Services. 